\title{
Proceeding
}

Supplementary Issue: Winter Conferences of Sports Science. Costa Blanca Sports Science Events, 22-23 March 2021. Alicante, Spain.

\section{Biofeedback in sport and education}

\author{
MARIANNA LIPAROTI $\triangle$, EMAHNUEL TROISI LOPEZ \\ Department of Motor Sciences and Wellness, University of Naples "Parthenope", Italy
}

\begin{abstract}
Usually, the term training is used to indicate a workout that aims to improve the physical performance of athletes. However, it is important to consider that training does not only affect physical features but also influences several cognitive components, consequently different behavioural expressions. This study aims to collect the main scientific evidence on the role of training based on biofeedback signals. Biofeedback is a technique useful not only for recognizing, evaluating and modulating different physiological responses but also for preventing any alterations and trauma. This work could be very important especially in the sports field, where training based on biofeedback, could be decisive for an improvement in the athlete's performance.
\end{abstract}

Keywords: Biofeedback; Sport; Education; Physical activity; Performance.

\section{Cite this article as:}

Liparoti, M., \& Lopez, E.T. (2021). Biofeedback in sport and education. Journal of Human Sport and Exercise, 16(3proc), S922-S929. https://doi.org/10.14198/ihse.2021.16.Proc3.09

\footnotetext{
Corresponding author. Department of Motor Sciences and Wellness, University of Naples "Parthenope", Italy. https://orcid.org/0000-0003-2192-6841

E-mail: marianna.liparoti@uniparthenope.it

Abstract submitted to: Winter Conferences of Sports Science. Costa Blanca Sports Science Events, 22-23 March 2021. Alicante, Spain.

JOURNAL OF HUMAN SPORT \& EXERCISE ISSN 1988-5202.

(c) Faculty of Education. University of Alicante.

doi:10.14198/jhse.2021.16.Proc3.09
}

S922 | 2021| Proc3|VOLUME 16

(C) 2021 University of Alicante 


\section{INTRODUCTION}

When it comes to athlete training, the first thought automatically refers to the physical training, glossing over a whole range of non-physical activities (Slimani et al., 2017; Stamatis et al., 2020; Walton et al., 2018) that the athlete has the task to carry out. Mental training, cognitive training and similar practices are part of a training methodology that directly affects the athlete's mind and are effectively involved into different area of study, including psychobiological and neurophysiological (Gee, 2010; Ranganathan et al., 2004; Rozand et al., 2014; Slimani et al., 2017). While it is true that the athlete's performance is highlighted by the power and precision of his muscles, it should not be forgotten that the musculoskeletal system acts under the direct control of the nervous system (Ludwig and Varacallo, 2017; Rodrigues et al., 2019). The latter in turn, in addition to being in constant communication with the rest of the body, operates several factors that are not always under the voluntary control of the individual. Anxiety, stress, fear and many other emotions play a fundamental role in altering the inputs received by the human body, with the risk of affecting the athlete's performance (Ford et al., 2017).

The purpose of neurophysiological training techniques is precisely to improve the athlete's ability to manage emotional states, such as anxiety (Goessl et al., 2017; Weerdmeester et al., 2020), in order to recover the normal psychophysical balance necessary for the realization of a positive performance.

Specifically, the paper will deal with a technique called biofeedback, a process through which the athlete learns to recognize, evaluate and modulate his physiological responses (Malik and Dua, 2020; Schwartz, 1979; Yu et al., 2018) with the aim of preventing, reducing or eliminating alterations. Learning this technique takes place through the help of equipment able to transform psychophysiological parameters into visual or acoustic signals, with the aim of offering the athlete an appreciable perception of these parameters. The ultimate goal will be to transfer what was learned during training to competition.

We live in a context where physical training is globally homologated, and the athlete's ability to withstand the anxiety and stress conditions present during the performance (Stults-Kolehmainen and Sinha, 2014) can make the difference between success and defeat.

To date, this technique is under-exploited and training continues to focus mainly on purely physical aspects. The purpose of this paper is to show the different areas of use of biofeedback and its potential, as well as to offer an analysis of this information and consistent proposals for any future implementation of biofeedback.

\section{BIOFEEDBACK}

Biofeedback is a psychophysiological training technique used in several fields from cognitive rehabilitation, to sport training (Frank et al., 2010; Jacini et al., 2018; Malik and Dua, 2020). The goal of this technique is to obtain, by the athlete, the control of important physiological responses with the aim of voluntarily achieving states of relaxation or activation (Sattar and Valdiya, 1999). This type of control, in addition to gaining confidence in the athlete, allows to effectively cope with highly stressful situations.

To achieve this goal, biofeedback uses equipment that can detect physiological parameters (Peake et al., 2018). After recording the parameter, these devices must be able to translate it and make it available to the athlete comprehension in the form of a beep or visual cue. In this way the athlete will be able to understand and appreciate the extent of physiological process concerning his own body but of which, without special instruments, he would not have been able to realize. It is precisely this kind of awareness that will allow the 
athlete to improve the control that he himself possesses on certain physiological parameters and consequently on the related processes.

Once the purpose of the training has been determined, the operator will choose the type of treatment to be carried out and which physiological functions related to motor performance to monitor (e.g. heart rate variability, dermal conductance level, respiratory rhythm, electroencephalography, etc.) (Monda et al., 2009; Russo et al., 2013; Sorrentino et al., 2019; Windthorst et al., 2015). At this point it is possible to make the first measurements for the acquisition of data that will represent the baseline on which, at the end of the training, it will be possible to make comparisons with the latest data collected. It should also be made clear that the significant results with regard to the autonomous ability to regulate certain physiological functions are not expected to be achieved from the beginning, while the purpose of the first sessions is first of all to make the athlete familiarize with the tools used and the new type of training (Malik and Dua, 2020).

The number of sessions may depend on several factors, such as the technique used, the purpose to be achieved. Since the purpose of such training is to transfer the skills learned from training to competition it is essential that the subject learns to replicate what he has learned even in the absence of the feedback received during the sessions.

Given the beneficial effects obtainable through its practice, biofeedback is used in multiple contexts and for various purposes. In fact, in addition to acting positively on a condition of a purely mental nature such as anxiety states, it can also be applied directly to the physical component, as in cases of health prevention and rehabilitation and motor re-education (Hsu et al., 2012; Polverino et al., 2020; Pourmomeny et al., 2014; Sielski et al., 2017).

In 2002, a task force composed of Association for Applied Psychophysiology and Biofeedback and Society for Neuronal Regulation (Moss and Gunkelman, 2002) outlined a series of levels of reliability of clinical efficacy in order to correctly assess the validity of psychophysiological interventions. Using these criteria, Yucha and Montgomery in 2008 ranked the current level of effectiveness of biofeedback training against different conditions and pathologies. Biofeedback has proved effective in counteracting factors such as anxiety, attention deficit disorder, chronic pain, high blood pressure (Yucha and Montgomery, 2008).

It can easily be deduced that the effective action of a biofeedback training in the presence of both pathological and non-pathological conditions such as those described above, can lead to a direct improvement in sports performance.

\section{BIOFEEDBACK IN SPORT}

Considered the beneficial effects offered by the biofeedback training, a research area crossing disciplines like sports psychology, biomechanics and physiology has grown, with the purpose to test and improve the methodologies of application of the biofeedback training technique. Dziembowska et al., conducted an interesting study on the use of biofeedback, analysing the anxiety symptoms of athletes and the variability of heart rate. Specifically, biofeedback was used as a stress management technique (Dziembowska et al., 2016) operating on the Heart Rate Variability (HRV). The set of tools used consisted of breathing techniques, voluntary generation of positive emotions and a portable biofeedback device for the real-time evaluation of physiological conditions. The parameters taken into account were HRV, electroencephalography information and self-assessment test about anxiety and self-esteem. The study involved 41 male athletes between the ages of 16 and 21. As results, the experimental group, unlike the control group, reduced the average levels 
of anxiety. In the experimental group there was also an improvement in the variability of heart rate and changes in the power spectra of alpha and theta brainwaves. Such changes are an indication of a better condition of both the central nervous system and the autonomic nervous system. According to this study a training based on biofeedback techniques applied to HRV can be a tool with beneficial effects with regard to stress management. For an athlete, reducing anxiety levels results in improved performance. Fewer distractions, less "weights" for our minds allow us to devote more attention and precision to the actions we carry out. In this case an athlete will be able to effectively dedicate his mental faculties to the realization of the required technical gesture. Moreover, possible improvements could be found in the reaction times and the speed in making choices in situations of great psychological pressure.

A further study conducted by Paul et al. (Paul et al., 2012), took into account physiological functions such as heart rate variability and respiratory rhythm, to see if an action on these parameters could affect performance elements such as reaction and movement times, concentration and shooting performance. The study was carried out on 30 basketball players (16 males and 14 females) aged 18-28. Regarding the psychological assessments, the results show a marked improvement in concentration for the experimental group while the placebo group and the control group did not change substantially. Concerning the physiological measurements, significant results have been obtained both in terms of heart rate variability and respiratory rhythm. Once again, the experimental group achieved significant improvements while there were no significant variations in the parameters of the other two groups. Moreover, concerning the sports performance, the experimental group was able to benefit from the training followed, obtaining an improvement in reaction times, unlike the other two groups in which no significant variation was found. Similar results were recorded assessing of shooting ability in which the experimental group obtained greater improvement compared to the other groups.

To conclude, an exhaustive review written by Morgan and Mora, specifically addressed the relationship between $\mathrm{HR}$ variability and sport performance, considering this training technique effective, safe and easy to learn and implement (Morgan and Mora, 2017).

\section{BIOFEEDBACK FOR INJURY PREVENTION IN SPORT}

Biofeedback showed its usefulness in the field of accident prevention too. During sports practice, both in training and in competition, the incorrect repetition of a movement can brings muscles or joints to excessive overload resulting in an injury. The method usually employed to prevent the risk of an injury and improve the technical gesture is neuromuscular training (Lardone et al., 2018; Montuori et al., 2019; Myer et al., 2013). This type of training aims to improve the communication between the nervous system and the muscles in such a way that the athlete improves the ability to coordinate and contract his muscles in the most efficient and precise way possible. The trainer usually provides the athlete with feedback during the execution of the technical gesture. Then the athlete must compare the information received and with the sensations that he himself perceives during the execution of the movement. This technique shows a great limitation, in fact it depends only on subjective evaluations, both of the athlete and of the trainer. In this case, a neuromuscular training combined with the use of biofeedback techniques can provide the athlete with real-time objective information about the physiological processes taking place in their body. In a critical analysis on injury prevention in sport, Kiefer et al. suggested how the use of specifical instruments can provide the athlete with an objective feedback that, combined with the skills of the trainer, manages to optimize training, also with regard to injury prevention, specifically referring to the prevention of rupture of the anterior cruciate ligament in young athletes (Kiefer et al., 2015). Combine this technique with advanced motion analysis, useful to precisely assess human movement both in healthy and pathological population (Liparoti et al., 2020, 2019; 
Minino et al., 2020; Rucco et al., 2020, 2019; Sorrentino et al., 2016; Troisi Lopez et al., 2021), can offer important tools for an effective rehabilitation.

\section{CONCLUSION}

Biofeedback training is a relatively new technique but that in recent years gained more and more favour in the field of sports psychology and interest from researchers. Although there is a need for more up-to-date and in-depth studies on a larger scale, the results are certainly promising (and in some cases evident). We believe that this type of training can represent in the future a pivotal element to be included in any sports practice and at any level. Most of the current training is concerned only with improving physical condition and through the repetition of the technical movement, with the aim of refining the technique. There are few training protocols that teach athletes to act on their physiological functions and for this reason biofeedback training can represent a turning point. If we also consider the benefits that this kind of training can bring also from the point of view of injury prevention, the reasons to include it among the standard training practices increase considerably. Furthermore, biofeedback training is effectively complementary to the training normally carried out during sports activity. On the one hand, it is able to increase quantitatively the skills available to the athlete, on the other hand it increases in quality those already in its possession. Finally, it should be remembered that, since the biofeedback training can act on a physiological level, the acquisition of these techniques becomes part of the normal habits of the subject. Consequently, any improvement that can be made in the sports field can also be transferred to everyday life. Specifically, it will also be possible to cope more effectively with situations of anxiety and stress that do not necessarily affect sports activities, and this inevitably means an improvement in the quality of life.

\section{REFERENCES}

Dziembowska, I., Izdebski, P., Rasmus, A., Brudny, J., Grzelczak, M., Cysewski, P., 2016. Effects of heart rate variability biofeedback on EEG alpha asymmetry and anxiety symptoms in male athletes: A pilot study. Appl. Psychophysiol. Biofeedback 41, 141-150. https://doi.org/10.1007/s10484-0159319-4

Ford, J.L., Ildefonso, K., Jones, M.L., Arvinen-Barrow, M., 2017. Sport-related anxiety: current insights. Open access J. Sport. Med. 8, 205. https://doi.org/10.2147/OAJSM.S125845

Frank, D.L., Khorshid, L., Kiffer, J.F., Moravec, C.S., McKee, M.G., 2010. Biofeedback in medicine: who, when, why and how? Ment. Health Fam. Med. 7, 85.

Gee, C.J., 2010. How does sport psychology actually improve athletic performance? A framework to facilitate athletes' and coaches' understanding. Behav. Modif. 34, 386-402. https://doi.org/10.1177/0145445510383525

Goessl, V.C., Curtiss, J.E., Hofmann, S.G., 2017. The effect of heart rate variability biofeedback training on stress and anxiety: a meta-analysis. Psychol. Med. 47, 2578. https://doi.org/10.1017/S0033291717001003

Hsu, H.-Y., Lin, C.-F., Su, F.-C., Kuo, H.-T., Chiu, H.-Y., Kuo, L.-C., 2012. Clinical application of computerized evaluation and re-education biofeedback prototype for sensorimotor control of the hand in stroke patients. J. Neuroeng. Rehabil. 9, 1-9. https://doi.org/10.1186/1743-0003-9-26

Jacini, F., Sorrentino, P., Lardone, A., Rucco, R., Baselice, F., Cavaliere, C., Aiello, M., Orsini, M., lavarone, A., Manzo, V., Carotenuto, A., Granata, C., Hillebrand, A., Sorrentino, G., 2018. Amnestic mild cognitive impairment is associated with frequency-specific brain network alterations in temporal poles. Front. Aging Neurosci. 10, 1-11. https://doi.org/10.3389/fnagi.2018.00400 
Kiefer, A.W., Kushner, A.M., Groene, J., Williams, C., Riley, M.A., Myer, G.D., 2015. A commentary on real-time biofeedback to augment neuromuscular training for $\mathrm{ACL}$ injury prevention in adolescent athletes. J. Sports Sci. Med. 14, 1.

Lardone, A., Liparoti, M., Sorrentino, P., Rucco, R., Jacini, F., Polverino, A., Minino, R., Pesoli, M., Baselice, F., Sorriso, A., Ferraioli, G., Sorrentino, G., Mandolesi, L., 2018. Mindfulness meditation is related to long-lasting changes in hippocampal functional topology during resting state: A magnetoencephalography study. Neural Plast. 2018. https://doi.org/10.1155/2018/5340717

Liparoti, M., Della Corte, M., Rucco, R., Sorrentino, P., Sparaco, M., Capuano, R., Minino, R., Lavorgna, L., Agosti, V., Sorrentino, G., 2019. Gait abnormalities in minimally disabled people with Multiple Sclerosis: A 3D-Motion Analysis study. Mult. Scler. Relat. Disord. https://doi.org/10.1016/i.msard.2019.01.028

Liparoti, M., Lopez, E.T., Agosti, V., 2020. Motion capture system: A useful tool to study cyclist's posture. Ludwig, P.E., Varacallo, M., 2017. Neuroanatomy, Central Nervous System (CNS).

Malik, K., Dua, A., 2020. Biofeedback - PubMed [WWW Document]. StatPearls [Internet]. Treasure IsI. StatPearls Publ. 2020.

Minino, R., Belfiore, P., Liparoti, M., 2020. Neuroplasticity and motor learning in sport activity. J. Phys. Educ. Sport 20.

Monda, M., Viggiano, An, Vicidomini, C., Viggiano, Al, lannaccone, T., Tafuri, D., De Luca, B., 2009. Expresso coffee increases parasympathetic activity in young, healthy people. Nutr. Neurosci. 12, 4348. https://doi.org/10.1179/147683009X388841

Montuori, S., D'Aurizio, G., Foti, F., Liparoti, M., Lardone, A., Pesoli, M., Sorrentino, G., Mandolesi, L., Curcio, G., Sorrentino, P., 2019. Executive functioning profiles in elite volleyball athletes: Preliminary results by a sport-specific task switching protocol. Hum. Mov. Sci. 63, 73-81. https://doi.org/10.1016/j.humov.2018.11.011

Morgan, S.J., Mora, J.A.M., 2017. Effect of heart rate variability biofeedback on sport performance, a systematic review. Appl. Psychophysiol. Biofeedback 42, 235-245. https://doi.org/10.1007/s10484$\underline{017-9364-2}$

Moss, D., Gunkelman, J., 2002. Task force report on methodology and empirically supported treatments: Introduction. https://doi.org/10.1300/J184v06n04 02

Myer, G.D., Kushner, A.M., Faigenbaum, A.D., Kiefer, A., Kashikar-Zuck, S., Clark, J.F., 2013. Training the developing brain, part I: cognitive developmental considerations for training youth. Curr. Sports Med. Rep. 12, 304-310. https://doi.org/10.1097/01.CSMR.0000434106.12813.69

Paul, M., Garg, K., Sandhu, J.S., 2012. Role of biofeedback in optimizing psychomotor performance in sports. Asian J. Sports Med. 3, 29. https://doi.org/10.5812/asjsm.34722

Peake, J.M., Kerr, G., Sullivan, J.P., 2018. A critical review of consumer wearables, mobile applications, and equipment for providing biofeedback, monitoring stress, and sleep in physically active populations. Front. Physiol. https://doi.org/10.3389/fphys.2018.00743

Polverino, A., Rucco, R., Stillitano, I., Bonavita, S., Grimaldi, M., Minino, R., Pesoli, M., Trojsi, F., D'Ursi, A.M., Sorrentino, G., 2020. In amyotrophic lateral sclerosis blood cytokines are altered, but do not correlate with changes in brain topology. Brain Connect. 10, 411-421. https://doi.org/10.1089/brain.2020.0741

Pourmomeny, A.A., Zadmehre, H., Mirshamsi, M., Mahmodi, Z., 2014. Prevention of synkinesis by biofeedback therapy: A randomized clinical trial. Otol. Neurotol. 35, 739-742. https://doi.org/10.1097/MAO.0000000000000217

Ranganathan, V.K., Siemionow, V., Liu, J.Z., Sahgal, V., Yue, G.H., 2004. From mental power to muscle power-gaining strength by using the mind. Neuropsychologia 42, 944-956. https://doi.org/10.1016/i.neuropsychologia.2003.11.018 
Rodrigues, A.C.Z., Messi, M.L., Wang, Z., Abba, M.C., Pereyra, A., Birbrair, A., Zhang, T., O'Meara, M., Kwan, P., Lopez, E.I.S., 2019. The sympathetic nervous system regulates skeletal muscle motor innervation and acetylcholine receptor stability. Acta Physiol. 225, e13195. https://doi.org/10.1111/apha.13195

Rozand, V., Lebon, F., Papaxanthis, C., Lepers, R., 2014. Does a mental training session induce neuromuscular fatigue? Med. Sci. Sport. Exerc. 46, 1981-1989. https://doi.org/10.1249/MSS.0000000000000327

Rucco, R., Liparoti, M., Agosti, V., 2020. A new technical method to analyse the kinematics of the human movements and sports gesture.

Rucco, R., Liparoti, M., Jacini, F., Baselice, F., Antenora, A., De Michele, G., Criscuolo, C., Vettoliere, A., Mandolesi, L., Sorrentino, G., Sorrentino, P., 2019. Mutations in the SPAST gene causing hereditary spastic paraplegia are related to global topological alterations in brain functional networks. Neurol. Sci. 40, 979-984. https://doi.org/10.1007/s10072-019-3725-y

Russo, C. V, Salvatore, E., Saccà, F., Tucci, T., Rinaldi, C., Sorrentino, P., Massarelli, M., Rossi, F., Savastano, S., Di Maio, L., 2013. Insulin sensitivity and early-phase insulin secretion in normoglycemic Huntington's disease patients. J. Huntingtons. Dis. 2, 501-507. https://doi.org/10.3233/JHD-130078

Sattar, F.A., Valdiya, P.S., 1999. Biofeedback in medical practice. Med. J. Armed Forces India 55, 51 54. https://doi.org/10.1016/S0377-1237(17)30315-5

Schwartz, G.E., 1979. Disregulation and systems theory: A biobehavioral framework for biofeedback and behavioral medicine. Biofeedback Self. Regul. 19-48.

Sielski, R., Rief, W., Glombiewski, J.A., 2017. Efficacy of biofeedback in chronic back pain: a metaanalysis. Int. J. Behav. Med. 24, 25-41. https://doi.org/10.1007/s12529-016-9572-9

Slimani, M., Taylor, L., Baker, J.S., Elleuch, A., Ayedi, F.M., Chamari, K., Cheour, F., 2017. Effects of mental training on muscular force, hormonal and physiological changes in kickboxers. J Sport. Med Phys Fit. 57, 1069-1107.

Sorrentino, P., Barbato, A., Del Gaudio, L., Rucco, R., Varriale, P., Sibilio, M., Strazzullo, P., Sorrentino, G., Agosti, V., 2016. Impaired gait kinematics in type 1 Gaucher's Disease. J. Parkinsons. Dis. 6, 191-195. https://doi.org/10.3233/JPD-150660

Sorrentino, P., Lardone, A., Pesoli, M., Liparoti, M., Montuori, S., Curcio, G., Sorrentino, G., Mandolesi, L., Foti, F., 2019. The development of spatial memory analyzed by means of ecological walking task. Front. Psychol. 10. https://doi.org/10.3389/fpsyg.2019.00728

Stamatis, A., Grandjean, P., Morgan, G., Padgett, R.N., Cowden, R., Koutakis, P., 2020. Developing and training mental toughness in sport: a systematic review and meta-analysis of observational studies and pre-test and post-test experiments. BMJ open Sport Exerc. Med. 6, e000747. https://doi.org/10.1136/bmisem-2020-000747

Stults-Kolehmainen, M.A., Sinha, R., 2014. The effects of stress on physical activity and exercise. Sport. Med. 44, 81-121. https://doi.org/10.1007/s40279-013-0090-5

Troisi Lopez, E., Minino, R., Sorrentino, P., Rucco, R., Carotenuto, A., Agosti, V., Tafuri, D., Manzo, V., Liparoti, M., Sorrentino, G., 2021. A synthetic kinematic index of trunk displacement conveying the overall motor condition in Parkinson's disease. Sci. Rep. 11, 1-11. https://doi.org/10.1038/s41598021-82348-4

Walton, C.C., Keegan, R.J., Martin, M., Hallock, H., 2018. The potential role for cognitive training in sport: more research needed. Front. Psychol. 9, 1121. https://doi.org/10.3389/fpsyg.2018.01121

Weerdmeester, J., van Rooij, M.M.J.W., Engels, R.C.M.E., Granic, I., 2020. An integrative model for the effectiveness of biofeedback interventions for anxiety regulation. J. Med. Internet Res. 22, e14958. https://doi.org/10.2196/14958 
Windthorst, P., Veit, R., Enck, P., Smolka, R., Zipfel, S., Teufel, M., 2015. Biofeedback and neurofeedback: applications in psychosomatic medicine and psychotherapy. Psychother. Psychosom. Med. Psychol. 65, 146. https://doi.org/10.1055/s-0034-1387320

Yu, B., Funk, M., Hu, J., Wang, Q., Feijs, L., 2018. Biofeedback for everyday stress management: a systematic review. Front. ICT 5, 23. https://doi.org/10.3389/fict.2018.00023

Yucha, C., Montgomery, D., 2008. Evidence-based practice in biofeedback and neurofeedback. AAPB Wheat Ridge, CO. 